\title{
Feasibility of Conservative Breast Surgery in Retroareolar Breast Cancer
}

\author{
Amr Samak ${ }^{1}$ MSc; Hosam Elfol' ${ }^{2}$ MD ; Soliman Elshakhs² MD
}

*Corresponding Author:

Amr Salem Samak

amrsamak@hotmail.com

Received for publication June 10, 2020; Accepted january 31. 2020; Published online january 31, 2020.

\section{Copyright 2021 The Authors published by Al-Azhar University, Faculty of Medicine, Cairo, Egypt. All rights reserved. This an open-access article distributed under the legal terms, where it is permissible to download and share the work provided it is properly cited. The work cannot be changed in anyway or used commercially.}

doi: 10.21608/aimj.2021.32104.1245

${ }^{1}$ General Surgery Department, El-Mokatem Health Insurance Hospital ,Egypt.

${ }^{2}$ General Surgery Department, Faculty of Medicine, Menoufia University, Menoufia , Egypt.

\begin{abstract}
ABSTRAC
Background: Centrally located tumors have long been thought to have high incidence of multi-centricity and multi-focality and classically treated with mastectomy .

Objective: is to evaluate the feasibility of breast conservative surgery in patients with retro-areolar breast cancer.

Methods: Eighteen female patients with Stage I or IIa retro-areolar breast cancer that were $\geq 1 \mathrm{~cm}$ away from nipple-areolar complex, were enrolled for our study at General Surgery Department, Menoufia University, from January 2014 to December 2015. Patients were fully assessed preoperatively. After patients' counseling and consent, all patients were subjected to lumpectomy with nipple-areola complex preservation. All patients were offered post-operative radiotherapy. Postoperative complications were recorded. Oncological and cosmetic outcome and patient satisfaction were evaluated.

Results: The resection margins of the excised mass were $1.283 \pm 0.583$ $\mathrm{cm}$ and were found to be clear of malignant cells in all patients. Axillary lymph nodes were positive for malignancy in 6 patients (33.33\%) (p 0.157). 13 patients $(72.22 \%)$ had invasive ductal carcinoma on postoperative histopathology (p 0.002). 6 patients developed postoperative complications ( $\mathrm{p}$ 0.001). Recurrence occurred only in 2 patients after 12 and 18 months (p 0.001). The cosmetic outcome was excellent in 9 patients, good in 7 patients and fair in 2 patients ( $\mathrm{p} 0.115$ ). 16 patients $(89 \%)$ were satisfied by the end results ( $\mathrm{p} 0.001$ ).

Conclusion: Breast conserving surgery is a feasible procedure for retroareolar breast cancer

Key Words: Retro-areolar breast cancer ; Breast conserving surgery ; Nipple-Areolar Complex preservation ; lumpectomy.
\end{abstract}

Disclosure: The authors have no financial interest to declare in relation to the content of this article. The Article Processing Charge was paid for by the authors.

Authorship: All authors have a substantial contribution to the article.

\section{INTRODUCTION}

Not only does the breast cancer brings the woman face to face with her mortality, but also its surgical treatment is accompanied by physical changes to the breast and body that may significantly, and often permanently, alter her perception of her physical, emotional, and sexual wholeness. ${ }^{1}$

The replacement of obligatory mastectomy by simple mastectomy or wide local excision and adjuvant radiotherapy, reflected a shift in the understanding of breast cancer pathology and biology. ${ }^{2}$ A balance between good cosmetic outcome and limiting the risk of recurrence remains the key to success. ${ }^{3}$

Centrally located tumors have long been thought to be associated with a higher incidence of multicentricity and multi-focality but more recent reports have failed to substantiate this specific correlation. ${ }^{4}$

For centrally-located breast cancer (CLBC), the nipple-areolar-complex (NAC) preservation surgery had not been generally recommended because of their highly malignant involvement but later on NAC preserving surgery was found to be clinically and oncologically sound treatment in NAC-free patients.
The aim of our study is to evaluate the feasibility of the breast conservative surgery in patients with retroareolar breast cancer.

\section{PATIENT AND MATERIALS}

Eighteen patients with Stage I or IIa retro-areolar breast cancer were included in our study at Department of General surgery, Menoufia University in the period from January 2014 to December 2015. Patients with advanced tumor, peripherally located tumors or tumor $<1 \mathrm{~cm}$ from the NAC were excluded from the study. Ethical clearance was taken before the start of the study from the ethical committee.

All patients were assessed preoperatively by full history taking including age of the patient, history of medical importance as smoking, past history of systemic diseases as diabetes, hypertension ... etc., history of previous breast diseases as breast masses, pain and nipple discharge, history of previous breast surgery, family history of breast cancer especially in first degree relative.

Also, assessment of the retro-areolar breast lump was done through examining its texture, mobility, fixation 
to the skin, underlying muscles, or chest wall and involvement of the NAC. Axillary lymph nodes were palpated for number and mobility. All patients in the study underwent complete blood count (CBC), coagulation profile, liver function tests, renal function tests and blood glucose level. Patients were also assessed radiologically by mammography, breast ultrasonography, chest $\mathrm{x}$-ray, abdominal ultrasonography and electrocardiography. The diagnosis of carcinoma of the breast was assured by preoperative needle biopsy or Tru-cut. All patients had counsel and consent for the procedure, risk, possible complications, re-do surgery or the need for immediate or delayed modified radical mastectomy.

In patients with tumor less than $1 \mathrm{~cm}$, immediate preoperative localization by sonar-guided wire insertion was done to obtain adequate symmetrical resection margins.

All patients were subjected to lumpectomy with NAC preservation. Treatment of axilla was done according to the stage of breast cancer.

During the procedure, the lesion was marked while the patient was awake to facilitate location of the tumor in the operating room. The patient was placed in the supine position with the arm abducted to 90 degrees. A circum-areolar incision was performed. The skin was then grasped with tissue forceps and electrocautery was used to dissect subareolarly to create a nipple-areolar complex flap. The dissection continued to remove the mass. The wound was then closed using inverted 3-0 absorbable Vicryl sutures and sub-cuticular 4-0 or 5-0 sutures. Axillary lymph node management was done through a separate axillary incision. Suction drains were placed. Axillary lymph node management was done through a separate axillary incision.

All patients were discharged from the ward $24 \mathrm{~h}$ after operation with suction drain and with proper antibiotics. Follow up of suction drain for hemorrhage or seromas. Aesthetic and oncological outcome and patient satisfaction for distortion, malposition, asymmetry, contour, deformity and scar were evaluated.

The assessment was classified to short term observation after one week and long term follow-up every 3 months where the aesthetic and oncological outcome and patient satisfaction for distortion, malposition, asymmetry, contour, deformity and scar were evaluated. Follow up was done by clinical examination, mammography and breast ultrasonography and metastatic evaluation by chest $\mathrm{x}$-ray and abdominal ultrasound.

Data was collected and entered to the computer using SPSS (Statistical Package for Social Science) program version 13.0, SPSS Inc., Chicago, Illinois, USA for statistical analysis. Data entered as numerical or categorical, as appropriate. Quantitative data was shown as mean, SD, and range. Qualitative data was expressed as frequency and percentage. Statistical analysis was done using Chi-square (Goodness-of-fit) test for qualitative data and one sample t-test for quantitative data. P (probability) value will be considered to be of statistical significance if it is less than 0.01 .

\section{RESULTS}

Our study included eighteen patients; all of them were treated by lumpectomy with NAC preservation (Figure 1).

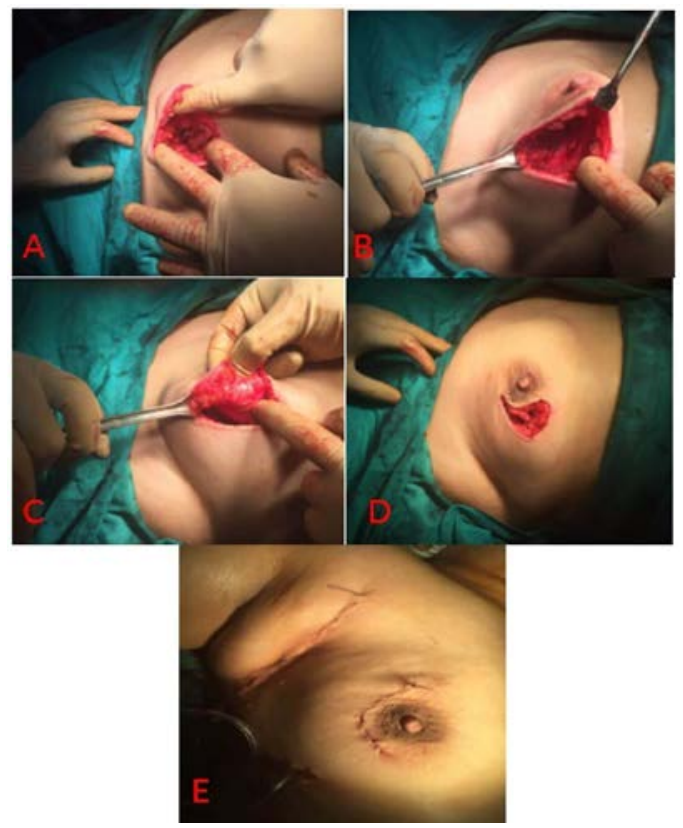

Fig. 1: A case of lumpectomy of a mass $1 \mathrm{~cm}$ deep to the NAC with NAC preservation.

(a) Shows the lump. (b) Shows the wound after removal of the lump. (c) Shows the retroareolar tissue after removal of the lump. (d) Shows the wound prior to closure. (e) Shows the wound after closure with axillary dissection and insertion of drains.

The age ranged from 31-59 years with a mean of $44.5 \pm 8.12$ years. Demographically, 12 patients (66.67\%) were pre-menopausal while only 6 patients were post-menopausal, 11 patients $(61.11 \%)$ were found to have positive past history of breast disease; 4 patients (22.22\%) had fibroadenosis and the remaining 7 patients (38.89\%) had biopsies in the form of fine needle aspiration, 4 patients (22.22\%) were found to have positive family history of breast cancer (Figure 2).

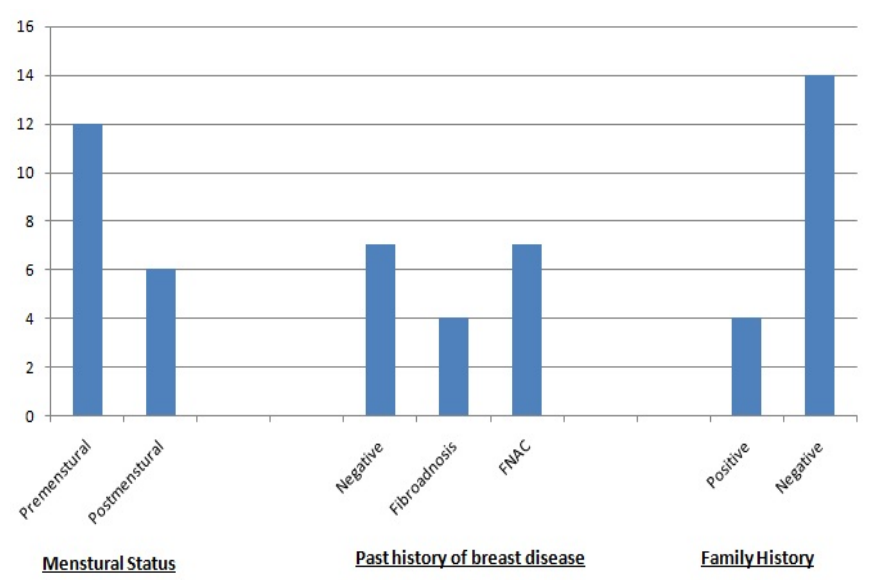

Fig. 2: Bar graph showing the demographic data among the patients. 
During the preoperative assessment, 11 patients (61\%) were found to have right retro-areolar breast mass while the remaining 7 patients (39\%) had left breast mass, 4 patients (22.22\%) were found to have a mass smaller than $1 \mathrm{~cm}$, twelve patients $(66.67 \%)$ with tumors ranging in size from 1 to $2 \mathrm{~cm}$ and two patients (11.11\%) with tumors larger than $2 \mathrm{~cm}$ with a mean of $1.7 \pm 0.78 \mathrm{~cm}$ with statistical significance (Table 1).

\begin{tabular}{|c|c|c|c|}
\hline \multicolumn{2}{|c|}{ Preoperative findings } & $\begin{array}{c}\text { Number of } \\
\text { patients }\end{array}$ & $\begin{array}{c}\text { p } \\
\text { value }\end{array}$ \\
\hline \multirow{2}{*}{$\begin{array}{c}\text { Side of the } \\
\text { affected breast }\end{array}$} & Right & $11(61.11 \%)$ & \multirow{2}{*}{0.346} \\
\cline { 2 - 3 } & Left & $7(38.89 \%)$ & \\
\hline \multirow{4}{*}{$\begin{array}{c}\text { Preoperative } \\
\text { mass size }\end{array}$} & $\begin{array}{c}<1 \\
\text { cm }\end{array}$ & $4(22.22 \%)$ & \\
\cline { 2 - 3 } & $\begin{array}{c}1-2 \\
\text { cm }\end{array}$ & $12(66.67 \%)$ & \multirow{2}{*}{0.009} \\
\cline { 2 - 3 } & $\begin{array}{c}>2 \\
\mathrm{~cm}\end{array}$ & $2(11.11 \%)$ & \\
\hline
\end{tabular}

Table 1: Preoperative findings among the patients

Regarding nipple-tumor distance ( $\mathrm{N}-\mathrm{T}$ distance), the minimum distance was $1 \mathrm{~cm}$ while the maximum distance was $3 \mathrm{~cm}$ with a mean of $1.933 \pm 0.556 \mathrm{~cm}$ (Figure 3).

\section{N-T Distance}

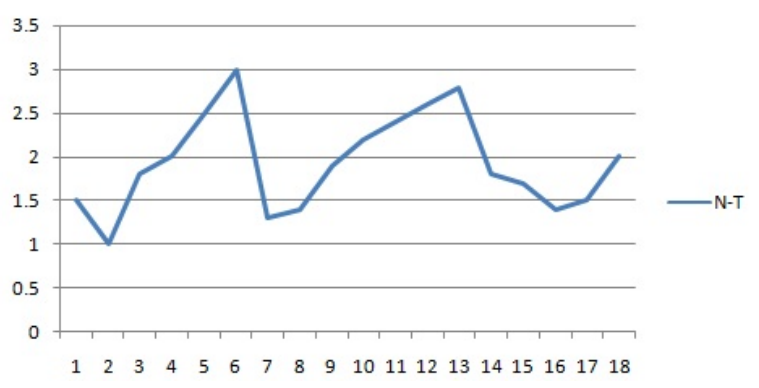

Fig. 3: Line graph showing the nipple-tumor distance.

By postoperative histopathology, the mean size of the excised mass was $2 \pm 0.88 \mathrm{~cm} .9$ patients $(50 \%)$ had tumors $<2 \mathrm{~cm}$ (T1 stage) while the remaining belong to T2 stage with tumor size ranging from $2-4 \mathrm{~cm}$. The resection margins of the excised mass were $1.283 \pm 0.583 \mathrm{~cm}$ and were found to be clear of malignant cells. Axillary lymph nodes were positive for malignancy in 6 patients (33.33\%) in whom axillary clearance was done.

13 patients (72.22\%) were found to have invasive ductal carcinoma, 3 patients $(16.67 \%)$ with invasive lobular carcinoma and 2 patients (11.11\%) with invasive mixed carcinoma with statistical significance. 5 patients (27.78\%) were stage I breast cancer with T1 N0 M0 stage while the remaining (72.22\%) were stage II breast cancer with T1 N1 M0 (4 patients) or T2 N0 M0 stages (9 patients) (Table 2).

\begin{tabular}{|c|c|c|c|}
\hline \multicolumn{2}{|c|}{ Histological findings } & $\begin{array}{c}\text { Number } \\
\text { of } \\
\text { patients }\end{array}$ & $\begin{array}{c}\text { p } \\
\text { value }\end{array}$ \\
\hline \multirow{4}{*}{$\begin{array}{c}\text { Axillary } \\
\text { Lymph node }\end{array}$} & Positive & $\begin{array}{c}6 \\
(33.33 \%)\end{array}$ & \multirow{2}{*}{0.157} \\
\cline { 2 - 3 } & Negative & $\begin{array}{c}12 \\
(66.67 \%)\end{array}$ & \\
\hline \multirow{4}{*}{$\begin{array}{c}\text { Histological } \\
\text { type }\end{array}$} & $\begin{array}{c}\text { Invasive } \\
\text { ductal } \\
\text { carcinoma }\end{array}$ & $\begin{array}{c}13 \\
(73.22 \%)\end{array}$ & \\
\cline { 2 - 3 } & $\begin{array}{c}\text { Invasive } \\
\text { carcinoma }\end{array}$ & $\begin{array}{c}3 \\
(16.67 \%)\end{array}$ & \multirow{2}{*}{0.002} \\
\cline { 2 - 3 } & $\begin{array}{c}\text { Invasive } \\
\text { mixed } \\
\text { carcinoma }\end{array}$ & $\begin{array}{c}2 \\
(11.11 \%)\end{array}$ & \\
\hline \multirow{4}{*}{$\begin{array}{c}\text { TNM } \\
\text { classification }\end{array}$} & T1 N0 M0 & $\begin{array}{c}5 \\
(27.78 \%)\end{array}$ & \multirow{2}{*}{0.311} \\
\cline { 2 - 3 } & T1 N1 M0 & $\begin{array}{c}4 \\
(22.22 \%)\end{array}$ & \\
\cline { 2 - 3 } & T2 N0 M0 & $\begin{array}{c}9(50 \%) \\
\end{array}$ & \\
\hline
\end{tabular}

Table 2: The histological findings among the patients

Three patients (16.67\%) had wound infection, 2 patients $(11.11 \%)$ had seroma in the subcutaneous tissue and only 1 patient (5.5\%) had partial slough of the NAC. All these patients responded to medical treatment. The other 12 patients $(66.66 \%)$ had no complications. The difference was statistically significant (Table 3).

\begin{tabular}{|c|c|c|}
\hline $\begin{array}{c}\text { Postoperative } \\
\text { Complications }\end{array}$ & $\begin{array}{c}\text { Number of } \\
\text { patients }\end{array}$ & $\begin{array}{c}\text { p } \\
\text { value }\end{array}$ \\
\cline { 1 - 2 } Wound infection & $3(16.67 \%)$ & \\
\cline { 1 - 2 } Seroma & $2(11.11 \%)$ & \multirow{2}{*}{0.001} \\
\cline { 1 - 2 } NAC complication & $1(5.55 \%)$ & \\
\cline { 1 - 2 } Negative & $12(66.67 \%)$ & \\
\hline
\end{tabular}

Table 3: Postoperative Complications among the patients

Regarding the oncological outcome, recurrence occurred only in 2 patients. Recurrence occurred after 12 months in the first patient while it occurred after 18 months in the second patient. This was significant statistically (Table 4).

\begin{tabular}{|c|c|c|c|c|}
\hline \multicolumn{2}{|c|}{$\begin{array}{c}\text { Oncological } \\
\text { Outcome }\end{array}$} & $\begin{array}{c}\text { Number of } \\
\text { patients }\end{array}$ & Percentage & $\begin{array}{c}\text { p } \\
\text { value }\end{array}$ \\
\hline \multirow{2}{*}{ Recurrence } & $-v e$ & 16 & $88.89 \%$ & \multirow{2}{*}{0.001} \\
\cline { 2 - 4 } & + ve & 2 & $11.11 \%$ & \\
\hline
\end{tabular}

Table 4: Oncological Outcome among the patients The cosmetic outcome was assessed by using the questionnaire made by Tzafetta and colleagues in 2011 (Figure 4). ${ }^{6}$ 


Shape with brassiere
I excellent
II good
III fair
IV poor
Shape without brassiere
I excellent
II good
III fair
IV poor
Contralateral match
I excellent match
II good match
III fair match
IV poor match
Mobility
I normal movement
II less mobile, no tethering
III tethering
IV immobile
Inframammary fold
I well-defined and symmetrical
II well-defined and asymmetrical
III ill-defined
Consistency
I soft
II firm
III hard
Overall result
I excellent
II good
III fair
IV poor

Fig. 4: The questionnaire used for cosmetic assessment

The cosmetic outcome was excellent in 9 patients, good in 7 patients and fair in only 2 patients. 16 patients were satisfied by the end results. This was significant statistically (Table 5).

\begin{tabular}{|c|c|c|c|c|}
\hline \multicolumn{2}{|c|}{ Variable } & $\begin{array}{c}\text { Number } \\
\text { of } \\
\text { patients }\end{array}$ & Percentage & $\begin{array}{c}\text { P- } \\
\text { value }\end{array}$ \\
\hline \multirow{3}{*}{$\begin{array}{c}\text { Cosmetic } \\
\text { outcome }\end{array}$} & Excellent & 9 & $50 \%$ & \\
\cline { 2 - 4 } & Good & 7 & $38.89 \%$ & \multirow{2}{*}{0.115} \\
\cline { 2 - 4 } & Fair & 2 & $11.11 \%$ & \\
\hline \multirow{2}{*}{$\begin{array}{c}\text { Patient } \\
\text { Satisfaction }\end{array}$} & Yes & 16 & $88.89 \%$ & \multirow{2}{*}{0.001} \\
\cline { 2 - 4 } & No & 2 & $11.11 \%$ & \\
\hline
\end{tabular}

Table 5: Cosmetic Outcome among the patients

\section{DISCUSSION}

Patients with central tumors involving or close to the Nipple-Areola-Complex (NAC) account for 5 to 20\% of breast cancer cases and, for a long time, they have routinely been denied the opportunity for breast conservation.,8 They have long been accused of being associated with a high incidence of multicentricity and multi-focality. Moreover, in the majority of these cases, sound oncologic surgery requires excision of the NAC with the central part of the breast which yields unacceptable cosmetic results. ${ }^{9}$

There are several predictive indicators of NAC involvement have been studied including tumor size, tumor distance from the nipple, node status and multi-centricity or multi-focality.

Cense and colleagues in 2001 reviewed the literatures dealing with NAC involvement, and concluded that the most important predictors were the nipple-tumor distance and the tumor size. ${ }^{10}$ Loewen and colleagues in 2008 concluded that the mammographic distance between the nipple and the tumor is independently predictive of NAC involvement. ${ }^{11}$ We used the nipple-tumor distance as a predictor for NAC involvement.

Rulli and colleagues in 2013 showed that a nippletumor distance less than $2.5 \mathrm{~cm}$ was considered as exclusion criteria from nipple-sparing while the distance used in Crowe and colleague study was $>1$ $\mathrm{cm}^{12,13}$ Crowe and others in 2004, who used the 1 $\mathrm{cm}$ as a cut-off for nipple sparing, had no recurrence among their 48 patients. ${ }^{13}$ They had only 3 patients with partial NAC slough. This made the Nippletumor distance of $1 \mathrm{~cm}$ as an appropriate distance for nipple preservation.

In our study, the distance between the mass and the NAC ranged $1-3 \mathrm{~cm}$ with a mean of $1.9 \pm 0.56 \mathrm{~cm}$.

The age of the patients ranged from 31 years to 59 years with a mean of $44.5 \pm 8.12$ years. This was lower than Rulli and colleagues study in 2013 where the mean of age was 50 years with the age of the patients ranged from 32 years to 74 years. ${ }^{12}$ About $75 \%$ of our patients had an age below 50 years. In Ren and colleagues study, $82 \%$ of patients were below 50 years. ${ }^{14}$ Most of the patients were premenopausal (66.67\%) with positive past history of breast disease (61.11\%), negative family history (77.78\%) and predominately right breast mass in 11 patients $(61.11 \%)$ with no impact on the operative procedure or the postoperative findings.

Data on the oncological reliability and feasibility of nipple preservation have been analyzed in many studies. Several authors have assessed the risk of sub-areolar recurrence after this surgical technique. It was found that sub-areolar recurrence risk increases with increasing tumor size. ${ }^{12}$

The mean size of tumors determined pathologically was $2 \pm 0.883 \mathrm{~cm}$ with a range of $0.7-4 \mathrm{~cm}$. While in Rulli and colleagues study, the mean size was $1.3 \mathrm{~cm}$ with a range of $0.2-2.5 \mathrm{~cm} .{ }^{12}$

Central breast tumors represent a challenge to the surgeon who must fulfill the fundamental goals of BCS, namely adequate margins and acceptable appearance. ${ }^{7}$ In all patients, the resection margins after excision were negative for any residual neoplasm.

The mean of the resection margin was $1.283 \pm 0.583$ $\mathrm{cm}$ with a range of $0.2-2 \mathrm{~cm}$. Ren and colleagues in 2014 made resection-free margins of $>1 \mathrm{~cm}$ in all patients. They stated that all patients with preservation of the NAC must obtain a negative surgical margin. ${ }^{14}$

Positive axillary lymph nodes were found in one third of the patients (6 Patients). All of them were movable and belonged to level I or II on the same side of the affected breast. Axillary lymph node clearance was completed in whenever positive one or both axillary lymph node levels were encountered (6 patients). In Ren study, it was positive in 27 out of 91 patients $(17 \%) .{ }^{14}$ This discrepancy is due to small number of patients in our study. 
The incidence of positive axillary nodes was 33.3\% while it was $43.5 \%$ in other studies. ${ }^{7}$ These incidences are lower than the reported incidence with breast cancer of all stages at the National Cancer Institute that ranges from $62 \%$ to $96.5 \%$. This is probably due to early case selection and less number of patients.

All the tumors in this study were found to be invasive with the predominance of the invasive ductal carcinoma (IDC) in 13 patients (72.22\%) (p 0.002) while in the study of Ren and others, 61 patients (67\%) were found to have (IDC) but they had 12 patients (13\%) diagnosed with ductal carcinoma insitu (DCIS) with no patient in our study had such diagnosis. ${ }^{14}$

One patient (5.56\%) developed partial slough of the NAC. In Rulli and colleagues study, most patients reported lack of sensitivity of the nipple skin postoperatively $^{12}$ while in Crowe and colleagues study, 3 patients reported partial slough of the NAC. Crowe claimed that superficial tissue loss of the NAC was common during the first 7 to 21 postoperative days but the 45 lumpectomy with nipple preservation performed through a lateral incision are completely intact and well healed, with good cosmesis. ${ }^{13}$

Half of the patients (9 patients) had Excellent cosmetic outcome and 7 patients (39\%) had Good outcome. This is different from the results reported by Wagner and colleagues in 2007 who reported Excellent up to $80 \%$, and Good up to $20 \%{ }^{15}$

Sixteen patients $(88.87 \%)$ were satisfied with the results (p 0.001). Most patients were satisfied because they preserved their breasts despite of the presence of the cancer. Both patients, who were not satisfied, were found to have eventful postoperative course. Both had postoperative wound infection that required frequent dressings and antibiotics administration for about one month that resulted in fair cosmetic outcome.

Follow-up was done every 3 months. Follow-up was done by using the clinical examination and radiological investigations. Only 2 patients $(11.11 \%)$ had recurrence after 12 and 18 months (p 0.001). Both patients had stage II breast cancer with T2 N0 M0 with negative sentinel lymph node. They received postoperative radiotherapy but they were found to have narrow resection margins of only 2 and $4 \mathrm{~mm}$ respectively. Both patients had modified radical mastectomy.

\section{CONCLUSION}

Breast conserving surgery is a suitable procedure for early retroareolar breast cancer. It is safe oncologically with no locoregional recurrence and good cosmetic outcome with good patient satisfaction.

\section{REFERENCES}

1. Holmes D., Schooler W. and Smith R.: Oncoplastic approaches to breast conservation. International Journal of Breast Cancer. 2011; Article ID 303879.

2. White J., Achuthan R., Turton P. and Lansdown M.: Breast Conservation Surgery: State of the art.
International Journal of Breast Cancer. 2011; Article ID 107981.

3. Khafagy M., Fakhr I., Hamed A. and Youssef O.: Pedicled dermoglandular flap reconstruction following breast conserving surgery. Journal of Egyptian National Cancer Institute. 2012; 24: 91-6.

4. Mascaro A., Farina M., Gigli R., Vitelli C. and Fortunato L.: Recent advances in the surgical care of breast cancer patients. World Journal of Surgical Oncology. 2010; 8:5.

5. Kimoto T., Sakao J., Shibakita M. , Kimura T., Akedo H. and Inoue Y.: Nipple-Areolar-Complex Sparing Breast-Conserving Surgery as an Acceptable Treatment Option for Patients With Centrally-located Breast Cancer: a Case Report. J. Med. Sci. 2009; 26:37-43.

6. Tzafetta K., Ahmed O., Bahia H., Jerwood D. and Ramakrishnan V.: Evaluation of the factors related to postmastectomy breast reconstruction. Plastic and reconstructive surgery. 2001; 107(7): 1694-701.

7. Naguib S.: Oncoplastic resection of retroareolar breast cancer: central quadrantectomy and reconstruction by local skin-glandular flap. Journal of the Egyptian National Cancer Institute. 2006; 18(4): 334-47.

8. Moustafa A. and Fakhr I.: Outcome of different oncoplastic surgical (OPs) techniques for centrally located breast cancer (CLBC). Journal of the Egyptian National Cancer Institute. 2014; 26: 203-9.

9. Pezzi C., Kukora J., Audet I., Herbert S., Horvick D. and Richeter M.: Breast Conservation Surgery Using Nipple-Areolar Resection for Central Breast Cancers. Arch Surg. 2004; 139:32-7.

10. Cense H., Rutgers E., Cardozo M. and Lanschot J.: Nipple-sparing mastectomy in breast cancer: a viable option? Eur J Surg Oncol. 2001; 27:521-6.

11. Loewen M., Jennings J., Sherman S., Salikeu J., Ebrom P., Davis A. et al.: Mammographic distance as a predictor of nipple-areola complex involvement in breast cancer. The American Journal of Surgery. 2008; 195:391-5.

12. Rulli A., Caracappa D., Barerini F., Boselli C., Cirocchi R., Castellani E. et al.: Oncologic Reliability of Nipple-sparing Mastectomy for Selected Patients with Breast Cancer. In vivo. 2013; 27:387394.

13. Crowe J., Kim J., Yetman R., Banbury J., Patrick R. and Bayenes D.: Nipple-sparing mastectomy: Technique and results of 54 procedures. Arch Surg. 2004; 139(2):148-50.

14. Ren Z., Li X., Xu X., Xia L. and Tang J.: Oncoplastic Breast Conserving Surgery with Nippleareolar Preservation for Centrally Located Breast Cancer: a Retrospective Cohort Study. Asian Pacific Journal of Cancer Prevention. 2014; 15:4847-9.

15. Wagner E., Shrank P., Hummer G., Sir A., Schreiner M. and Wayand W.: Central Quadrantectomy with Resection of the Nipple-Areola Complex Compared with Mastectomy in Patients with Retroareolar Breast Cancer. The Breast Journal. 2007; 13(6):557-63. 